\title{
Effects of Course Length on the Six-Minute Walk Test in Healthy Adults: A Pilot Study
}

\section{Woods L*}

Alabama State University Montgomery, USA

*Corresponding author: LaDarius Woods, Alabama State University Montgomery, USA, P.O. Box 271 Montgomery, AL 36101, Tel: 3342298808; Email: lwoods@alasu.edu

\section{Pilot Study}

Volume 6 Issue 1

Received Date: April 27, 2021

Published Date: May 11, 2021

DOI: $10.23880 /$ oajprs-16000140

\section{Abstract}

Introduction: The 6 Minute Walk Test (6MWT) is an easy and effective way to measure functional capacity, track progress/ regression of interventions, and predict morbidity and mortality. According to the protocol of the American Thoracic Society (ATS), the ideal course length for the 6 MWT is $30 \mathrm{~m}$. Unfortunately, most clinics do not have sufficient space to accommodate these guidelines. The purpose of this pilot study is to examine the effects of different course lengths on the 6MWT in healthy adults age 18-30, in addition to adding to the normative data for distanced walked.

Methods: A quasi-experimental design was used. Twenty-one healthy participants were randomly assigned to either the $15 \mathrm{~m}$ or $20 \mathrm{~m}$ walk group. Results were analyzed using a one- tailed paired samples t-test.

Results: Both the $15 \mathrm{~m}$ and $20 \mathrm{~m}$ groups demonstrated no difference in distance walked when compared to their $30 \mathrm{~m}$ trial. The mean distance walked in the $15 \mathrm{~m}$ groups was $544.28 \mathrm{~m}(\mathrm{SD}=46.15)$, with a $30-\mathrm{m}$ course distance walked as $614.54 \mathrm{~m}$ (SD $=65.81)$. The mean distance walked in the $20-\mathrm{m}$ group was $597.37 \mathrm{~m}(\mathrm{SD}=59.92)$ with a $30-\mathrm{m}$ distanced walked as $614.54 \mathrm{~m}$ $(\mathrm{SD}=65.81)$.

Discussion: Our study is one of the first to investigate distanced walked in healthy adults aged 18-30. Based on our results, we suggest that clinicians and researchers use their current space, albeit their space is at least $15 \mathrm{~m}$ with health adults. Further research is warranted to investigate course lengths relationship to distance walked in other population.

Keywords: Course length; Six-minute walk test; Healthy adults

\section{Introduction}

The 6 Minute Walk Test (6 MWT) is a simple and effective functional capacity measure that mimics activities of daily living [1-2]. The 6 MWT assesses submaximal exercise tolerance by measuring the distance someone can walk within six minutes at their self-selected speed and has been reported to predict morbidity and mortality in individuals with moderate to severe cardiovascular and lung disease, track progress and regression of therapeutic interventions, and qualitatively provide clinicians and researchers the ability to observe gait asymmetries [1-4]. Self- selected speed and minimal equipment of a stopwatch, chair, and hallway are distinct clinical advantages the 6 MWT has on similar functional capacity measures such as the shuttle and treadmill fitness test and makes the 6 MWT an ideal choice in clinical environments [5-7].

The American Thoracic Society [3] outlined the 6 MWT should be performed indoors, along a flat, straight, and 


\section{Open Access Journal of Pulmonary \& Respiratory Sciences}

enclosed hallway of at least $30 \mathrm{~m}$ where minimal to no traffic is noted. The American Thoracic Society [3] rationalized a shorter hallway would reduce distance walked.

Additional variables, which influenced distance walked, include gender, age, height, weight, perceived exertion, heart rate, fitness, and country of residence $[2,5,8]$. Each of those aforementioned variables is non-modifiable by the clinician or researcher prior to implementation of an intervention. A modifiable variable for clinicians and researchers is hallway or course length.

Beekman, et al. [1] reported a $49.5 \mathrm{~m}$ difference when comparing a $30 \mathrm{~m}$ course with a $10 \mathrm{~m}$ course in patients with chronic obstructive pulmonary disease population. $\mathrm{Ng}$, et al. [9] found a $14 \mathrm{~m}$ difference when comparing a $30 \mathrm{~m}$ course to a $20 \mathrm{~m}$ course, $41 \mathrm{~m}$ difference when comparing a $30 \mathrm{~m}$ course to a $10 \mathrm{~m}$ course, and a $21 \mathrm{~m}$ difference when comparing a $20 \mathrm{~m}$ course to a $10 \mathrm{~m}$ course. Similarly, Klein, et al. [10] reported a $22.1 \mathrm{~m}$ difference when comparing a $30 \mathrm{~m}$ course with a $20 \mathrm{~m}$ course. Klein, et al. [10] also found performance to be a moderate indicator of distance walked. Gochicoa-Rangel, et al. [11] reported a mean difference of $25 \mathrm{~m}$ in their healthy control group and $17 \mathrm{~m}$ in their chronic lung disease group when comparing a $15 \mathrm{~m}$ and $30 \mathrm{~m}$ course. Of note, GochicoaRangel, et al. [11] reported a Pearson correlation of 0.85 and 0.96 within their healthy control group and chronic lung disease groups, respectively. Lastly, Trooster, Gosselink, \& Decramer [12] found the average distance walked for healthy older adults, aged $50-85$ was $631 \mathrm{~m}(\mathrm{SD}=93)$.

\section{Purpose of the Study}

In this pilot study, we wanted to compare the distance walked of a $30 \mathrm{~m}$ course with a $20 \mathrm{~m}$ and $15 \mathrm{~m}$ courses in a healthy, adult population age 18-30. The purpose of this study was to measure the effect of course length on distanced walked in healthy adults age 18-30. We hypothesized, that the longer the course length, the greater the distance walked. This study also sought to add to the normative data for the 18-30-year-old healthy, adult population.

\section{Methods}

We performed a prospective study over a four-month period in the Physical Therapy Department at Alabama State University in Montgomery, Alabama.

\section{Study Design}

Participants were recruited among college-aged students at Alabama State University and the surrounding community. Information letters outlining the aim of the study were distributed within the University and surrounding communities. A quasi-experimental study design was used. Approval for the study was obtained by the Alabama State University Institutional Review Board.

\section{Participants}

Twenty-four adults volunteered for the study. Inclusion criteria included: must be between the age of 18-30 and respond to yes to all items on the health questionnaire. Exclusionary criteria included: anyone below 18 years of age, adults older than 30, and anyone who answered no to any item on the health questionnaire.

\section{Protocol}

Participants were randomly assigned into two experimental groups, $15 \mathrm{~m}$ or $20 \mathrm{~m}$. In total, each participant completed two 6 MWTs. The $30 \mathrm{~m} 6$ MWT served as the control, while their randomly assigned $15 \mathrm{~m}$ or $20 \mathrm{~m}$ served as the experimental. Each of their 6 MWT were completed on different days. The order of completion was randomized, and the second test was performed between 2-21 days of the initial testing.

All 6 MWTs were performed in params defined by the American Thoracic Society [3] guidelines. Each participant was provided instructions in the information letter to wear comfortable walking shoes and clothes and to bring an ambulatory walking aid, if warranted in addition to not engaging in any vigorous exercise within two hours of their appointment time. All tests were performed in the same location, a quiet indoor hall with a flat, straight floor. The floor was marked at every five $m$ and traffic cones and a chair were placed to mark the turns of the 6 MWT course.

Each participant sat for ten minutes prior to starting the 6 MWT. After sitting for ten minutes, vitals of blood pressure, heart rate, and respiratory rate were taken. All vitals were taken by the same researcher. In addition, the participants were provided with instructions of the 6 MWT and a physical copy of the modified Borg scale. Verbal encouragement and vital monitoring were completed as outlined in the 6 MWT protocol. Lastly, vitals were taken immediately after the completion of the 6 MWT.

\section{Data Analysis}

The difference between the $15 \mathrm{~m}$ course and $30 \mathrm{~m}$ course distance walked was analyzed using a one-tailed, paired t-test. The difference between the $20 \mathrm{~m}$ course and $30 \mathrm{~m}$ course were analyzed using a one-tailed, paired t-test. $P$-values were to be considered significant if less than 0.05 . 


\section{Open Access Journal of Pulmonary \& Respiratory Sciences}

\section{Results}

An initial sample of twenty-four participants from the College of Health Science at Alabama State University, between the ages of 18 and 30, volunteered to participate in this study. Three participants data were excluded due to failure of participants to follow the outlined protocol.

\section{Demographic}

Demographic characteristics of all twenty-one participants are summarized in Table 1, including age, sex, and race-ethnicity. Cardiorespiratory vitals are summarized in Tables 2 \& 3.

\begin{tabular}{|c|c|}
\hline \multicolumn{2}{|c|}{ Characteristic } \\
\hline \multicolumn{2}{|c|}{ Sex $^{\mathbf{b}}$} \\
\hline Mean age ${ }^{\mathrm{a}}$ \\
\hline Male & $24.5(1.78)$ \\
\hline \multicolumn{2}{|c|}{ Race/Ethnicity $^{\mathbf{c}}$} \\
\hline African American & $13(62)$ \\
\hline Asian & $5(24)$ \\
\hline Hispanic, Latino, or Spanish Origin & $0(0)$ \\
\hline Middle Eastern or North African & $0(0)$ \\
\hline Native Hawaiian or Pacific Islander & $0(0)$ \\
\hline White (Non-Hispanic) & $0(0)$ \\
\hline
\end{tabular}

Table 1: Characteristics And Demographics Of All Participants.

${ }^{a}$ Mean age with Standard Deviation in parenthesis.

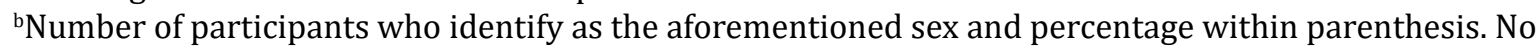
cparticipants identified outside of male and female.

Number of participants who identify with the race/ethnicity category and percentage within parenthesis.

\begin{tabular}{|c|c|c|c|c|}
\hline Participants $^{\mathbf{a}}$ & \multicolumn{2}{|c|}{ Before 6MWT $^{\mathbf{e}}$} & \multicolumn{2}{c|}{ Change following 6MWT $^{\mathbf{e}}$} \\
\hline Vitals & $15 \mathrm{~m}$ & $30 \mathrm{~m}$ & $15 \mathrm{~m}$ & $30 \mathrm{~m}$ \\
\hline Heart Rate $^{\mathrm{b}}$ & $67(9.34)$ & $68(11.21)$ & $90.2(16.01)$ & $86(14.20)$ \\
\hline Respiratory Rate $^{\mathrm{c}}$ & $16.7(3.13)$ & $16.18(3.51)$ & $19.5(4.91)$ & $19.3(5.39)$ \\
\hline Borg Exertion $^{\mathrm{d}}$ Scale & $0.7(0.64)$ & $0.36(0.67)$ & $2.18(1.45)$ & $2.3(1.89)$ \\
\hline
\end{tabular}

Table 2: Mean Cardiorespiratory Vitals For 15m And 30m.

${ }^{\mathrm{a}} \mathrm{n}=11$ participants.; ${ }^{\mathrm{b}} \mathrm{Heart}$ rate is measured in beats per min.; ${ }^{\mathrm{c}}$ Respiratory rate is measured in breaths per min.

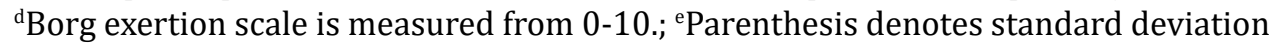

\begin{tabular}{|c|c|c|c|c|}
\hline Participants $^{\mathbf{a}}$ & \multicolumn{2}{|c|}{ Before the 6MWT $^{\mathbf{e}}$} & \multicolumn{2}{c|}{ Change following 6MWT $^{\mathbf{e}}$} \\
\hline Course Distance $^{\mathrm{e}}$ & $20 \mathrm{~m}$ & $30 \mathrm{~m}$ & $20 \mathrm{~m}$ & $30 \mathrm{~m}$ \\
\hline Heart Rate $^{\mathrm{b}}$ & $74.8(8.0)$ & $68.6(6.5)$ & $101.7(15.4)$ & $94.8(19.6)$ \\
\hline Respiratory Rate $^{\mathrm{c}}$ & $15.5(5.2)$ & $15.2(4.5)$ & $18.8(4.4)$ & $19.2(3.9)$ \\
\hline Borg Exertion $^{\mathrm{d}}$ & $0.2(0.3)$ & $0.2(0.4)$ & $2.8(1.6)$ & $2.7(1.8)$ \\
\hline
\end{tabular}

Table 3: Mean Cardiorespiratory Vitals For 20m And 30m.

${ }^{\mathrm{a}} \mathrm{n}=10$ participants.; ${ }^{\mathrm{b}}$ Heart rate is measured in beats per min.

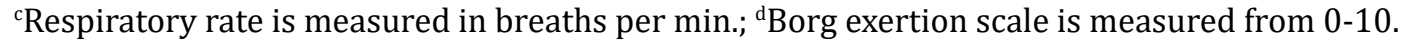

eParenthesis denotes standard deviation 


\section{Open Access Journal of Pulmonary \& Respiratory Sciences}

\section{Analysis}

There were eleven participants in group one, $15 \mathrm{~m}$ course length (Table 4). The mean distance walked for the $15 \mathrm{~m}$ course was $544.28 \mathrm{~m}(\mathrm{SD}=46.15)$ and the mean distance walked for the $30 \mathrm{~m}$ course was $562.31 \mathrm{~m} \mathrm{(SD}=28.37)$. A onetailed, paired t-test was conducted to determine if healthy adults walked further on the $30 \mathrm{~m}$ course when compared to the $15 \mathrm{~m}$ course. The distance walked served as the dependent variable. The results of the one-sample t-test was not significant, $\mathrm{t}(10)=-1.71, p=.06$. The effect size $(\mathrm{d}=47)$ was small. Thus, the results suggest that course length does not affect distanced walked in health adults (Table 4).
There were ten participants in group two, $20 \mathrm{~m}$ course length (Table 4). The mean distance walked for the $20 \mathrm{~m}$ course was $597.37 \mathrm{~m}(\mathrm{SD}=59.92)$ and the mean distance walked for the $30 \mathrm{~m}$ course was $614.54 \mathrm{~m}(\mathrm{SD}=65.81)$. A onetailed, paired t-test was conducted to determine if healthy adults walked further on the $30 \mathrm{~m}$ course when compared to the $20 \mathrm{~m}$ course. The distance walked served as the dependent variable. The results of the one-tailed, paired t-test was not significant, $\mathrm{t}(9)=-1.50, p=.08$. The effect size $(\mathrm{d}=.27)$ was small. Thus, the results suggest that course length does not affect distanced walked in healthy adults (See Table 4).

\begin{tabular}{|c|c|c|c|c|}
\hline Participants & \multicolumn{2}{|c|}{ Group 1 $^{\text {a }}$} & \multicolumn{2}{c|}{ Group 2 $^{\text {b }}$} \\
\hline Course Distance & $15 \mathrm{~m}$ & $30 \mathrm{~m}$ & $20 \mathrm{~m}$ & $30 \mathrm{~m}$ \\
\hline Distance Walked $^{\mathrm{c}}$ & $544.28(46.15)$ & $562.31(28.37)$ & $597.37(59.92)$ & $614.54(65.81)$ \\
\hline$P$ Value & \multicolumn{2}{|c|}{0.06} & \multicolumn{2}{c|}{0.08} \\
\hline Effect Size & \multicolumn{2}{|c|}{0.47} & \multicolumn{2}{|c|}{0.27} \\
\hline
\end{tabular}

Table 4: 6MWT Distance Walked.

${ }^{a}$ Group $1, n=11$ participants

${ }^{\mathrm{b}}$ Group 2, $\mathrm{n}=10$ participants

'Distance walked as measured in m. Parenthesis denotes standard deviation.

\section{Discussion}

Overall, healthy adults did not walk further on a $30 \mathrm{~m}$ course when compared to either a $15 \mathrm{~m}$ course $(p=.06)$ or a $20 \mathrm{~m}$ course $(p=.08)$. Our results are in contrast with previously reported scholars who found course length to affect distance walked [1,9-11] Although our study is inconsistent with previously reported literature, our study is one of the few that used healthy adults. Beck, et al. [1] concluded there was a difference in course length, when they compared a $10 \mathrm{~m}$ course to a $30 \mathrm{~m}$ course. The discrepancy between our results and theirs may be a result of a meaningful difference between $15 \mathrm{~m}$ and $10 \mathrm{~m}$, in addition to the sample population of participants of COPD when compared to our study of healthy adults. Overall, Beck, et al. [1] reported a shorter distance walked than our participants. $\mathrm{Ng}$, et al. [9] also concluded there was a difference in course length when comparing a $20 \mathrm{~m}$ course to a $30 \mathrm{~m}$ course. The discrepancy between our results and theirs may be attributed to the sample population of participants of adults with stroke when compared to our study with healthy adults. Similar to Beck, et al. [1], $\mathrm{Ng}$, et al. [9] reported an overall lower distanced ambulated than our participants. Gochicoa-Rangel, et al. [11], one of the few scholars to use healthy adults as a control group, were in agreement with our results when they concluded a $15 \mathrm{~m}$ distance can be used in patients with chronic lung disease. Gochicoa-Rangel, et al. [11] explained that if test administrators maintain intra-rater reliability by ensuring the same person is conducting the test, results can be interpreted as valid.
One explanation on why course length had no affect is due to the sample size of healthy adults aged 18-30. Our study was one of the first to focus on this age group. In agreement with Gochicoa-Rangel, et al. [11], we suspect the guidelines published in 2002 and 2014 concluded the $30 \mathrm{~m}$ course as the optimum course due to lack of published data demonstrating the validity and reliability of a shorter course distance. Another explanation why course length had no affect is the intra-rater reliability of our study. During our study, the same researcher conducted each portion, for each of the twenty-one participants. As Gochicoa-Rangel, et al. [11] the use of multiple test administrators may skew results. Lastly, since we allowed participants to complete each trial of the 6 MWT on separate days, this strengthened our internal validity [13-15].

Clinicians and researchers should note the additional factors such as height, weight, gender, age, body mass index, heart rate, perceived exertion, prior level of physical activity and socioeconomic status may predict or effect 6 MWT distance [2,5,8]. Mylius, et al. [8] highlighted in their systematic review of children and adolescents that due to the lack of homogeneity of study designs an ideal single reference value is impossible. A positive correlation has been reported with the male sex, height, prior physical activity level, heart rate, and perceived exertion, while a negative correlation has been reported with age and weight [2,8]. Lastly, Almeida, et al. [5] argued participants from countries with a higher percentage of low socioeconomic conditions may walk 


\section{Open Access Journal of Pulmonary \& Respiratory Sciences}

further, when compared to more affluent countries.

Based on our pilot data, there is support for clinicians can use their available space, albeit their space is at least $15 \mathrm{~m}$, when performing the 6 MWT on healthy adults aged $18-30$.

Additional studies are warranted to continue to add to the body of evidence supporting or refuting in patients with cardiopulmonary conditions and neuromusculoskeletal conditions, in addition to age stratifications.

\section{Conclusion}

In our pilot study, course length did not affect distance walked in healthy adults aged 18- 30 . These results are inconsistent with previous studies which outlined course length affected distance ambulated [1,9-11]. One explanation for this inconsistency is our sample size of age 18-30, healthy adults. Additional studies are warranted to continue to add to the normative data of health adults and to support or refute our conclusion of course length not affecting distance walked.

\section{Limitations}

A limitation of this study was that we used a convenience sample. Another limitation when interpreting the results is the lack of generalizability due to this being a pilot study. Lastly, the homogeneity of our sample may have influenced our results.

\section{References}

1. Beekman E, Mesters I, Hendriks EJ, Klaassen MPM, Gosselink R, et al. (2013) Course Length of 30 Ms versus 10 Ms Has a Significant Influence on Six-Minute Walk Distance in Patients with COPD: An Experimental Crossover Study. J Physio 59(3): 169-176.

2. Enright PL, McBurnie MA, Bittner V, Russell T, Robert MN, et al. (2003) The 6-Min Walk Test: A Quick Measure of Functional Status in Elderly Adults. Chest 123(2): 387-398.

3. American Thoracic Society (2002) ATS Statement: Guidelines for the Six-Minute Walk Test. AM J Respir Crit Care Med 166: 111-117.

4. Meir P, Wagner J, Adusumilli G, Gottlieb A, Naismith R (2020) Gait Asymmetry, and Bilateral Coordination of Gait During a Six-Minute Walk Test in Persons with Multiple Sclerosis. Sci Rep 10(1): 12382.

5. Almeida VP, Ferreira AS, Guimarães FS, Papathanasiou J, Lopes AJ (2019) Predictive Models for the Six-Minute
Walk Test Considering the Walking Course and Physical Activity Level. Eur J Phys Rehabil Med 55(6): 824-833.

6. Casanova C, Celli BR, Barria P, Casas A, Cote C, et al. (2011) The 6-Min Walk Distance in Healthy Subjects: Reference Standards from Seven Countries. Eur Respir J 37(1): 150-156.

7. Nathan SD, Du Bois RM, Albero C, Bradford WZ, Costabel U, et al. (2015) Validation of Test Performance Characteristics and Minimal Clinically Important Difference of the 6-Minute Walk Test in Patients with Idiopathic Pulmonary Fibrosis. Respir Med 109(7): 914922.

8. Mylius C, Paap, D, Takken, T (2016) Reference Value for the 6-Minute Walk Test in Children and Adolescents: A Systematic Review. Expert Rev Respir Med 10(12): $1335-1352$.

9. Ng S, Tsang W, Cheung T, Chung J, To F, et al. (2011) Walkway Length, but Not Turning Direction, Determines the Six-Minute Walk Test Distance in Individuals with Stroke. Arch Phys Med Rehabil 92(5): 806-811.

10. Klein SR, Gulart AA, Venâncio RS, Munari AB, Gavenda SG, et al. (2021) Performance Difference on the SixMinute Walk Test on Tracks of 20 and 30 Ms for Patients with Chronic Obstructive Pulmonary Disease: Validity and Reliability. Braz J Phys Ther 25(1): 40-47.

11. Gochicoa-Rangel L, Ramirez-Jose M, Troncoso-Huitron P, Silva-Cerón M, Guzmán-Valderrábano C, et al. (2020) Shorter Corridors Can be Used for the Six-Minute Walk Test in Subjects with Chronic Lung Disease. Respir Investig 58(4): 255-261.

12. Trooster T, Gosselink R, Decramer, M (1999) Six Minute Walking Distance in Healthy Elderly Subjects. Eur Respir J 14(12): 270-274.

13. Gibbons WJ, Fruchter N, Sloan S, Levy RD (2001) Reference Values for a Multiple Repetition 6- Minute Walk Test in Healthy Adults Older than 20 Years. J Cardiovasc Rehabil 21(2): 87-93.

14. Sciurba F, Criner GJ, Lee SM, Mohsenifar Z, Shade D, et al. (2003) Six-Minute Walk Distance in Chronic Obstructive Pulmonary Disease. Am J Respi Crit Care Med 167(11): 1522-1527.

15. Lui J, Drutz C, Kumar R, McVicar L, Weinberger R, et al. (2008) Use of the Six-Minute Walk Test Poststroke: Practice Effect? Ach Phys Med Rehabil 89(9): 1686-1692. 